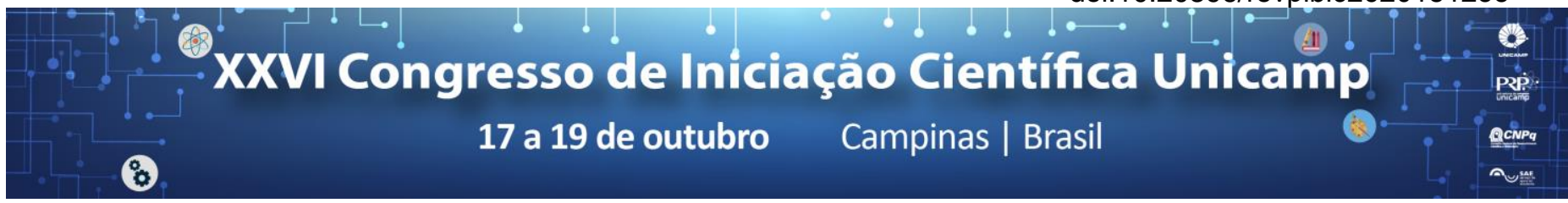

\title{
Análise da estatura final em meninas com puberdade precoce central tratada com análogo de GNRH.
}

\section{Sabrina Vieira Sanchez*, Daniela Angerame Yela Gomes.}

\section{Resumo}

A Puberdade Precoce Central Idiopática é a forma mais frequente de puberdade precoce em meninas, resultando em baixa estatura na vida adulta, sendo atualmente tratada com análogo de GNRH. Assim, fez-se um estudo retrospectivo, analisando o ganho de estatura de 53 meninas com tal diagnóstico e que utilizaram deste tratamento no Ambulatório de Ginecologia Endócrina do departamento de Tocoginecologia da Faculdade de Ciências Médicas da Unicamp, utilizando o teste de Wilcoxon para amostras relacionadas, e o programa SAS versão 9.2. Verificou-se diferença significativa entre as avaliações inicial e final para altura, idade óssea, FSH e LH das pacientes em questão, concluindo a eficácia do tratamento.

\section{Palavras-chave:}

Puberdade precoce, GNRHa, estatura final.

\section{Introdução}

Puberdade precoce, em meninas, consiste no aparecimento de caracteres sexuais secundários antes dos oito anos de idade. $\mathrm{Na}$ puberdade precoce verdadeira vê-se, além disso, uma redução da estatura final dessas meninas. A forma mais frequente de puberdade precoce é a idiopática, sendo seu pior efeito a baixa estatura na vida adulta, além do impacto psicológico causado pela mudança corporal.

Atualmente, uma opção que temos para o tratamento de meninas diagnosticadas com puberdade precoce verdadeira é o uso de análogo de GNRH. Assim sendo, o presente projeto tem como objetivo avaliar o ganho de estatura em meninas com esse diagnóstico e que utilizaram esse tratamento, comparando-a com a altura predita pelo método de Bayley Pinneau e com a altura alvo, analisando, então, a eficácia do tratamento.

\section{Resultados e Discussão}

- Em média, a idade de início dos sintomas dessas meninas era de sete anos e três meses, sendo que a idade final das mesmas, após o tratamento, foi de nove anos e meio.

- A média de tempo de tratamento com análago de GNRH foi de um ano e oito meses.

Em média, a altura dessas meninas no início dos sintomas era de $1,28 \mathrm{~m}$, e no final do tratamento de $1,40 \mathrm{~m}$, com um $\mathrm{P}<0,001$, significando que o ganho de altura médio dessas meninas foi significativo na vigência do tratamento em estudo.

- Em média, a idade óssea das meninas no início do tratamento era de nove anos e oito meses (dois anos e cinco meses a mais do que a média de idade em que ocorreu o início dos sintomas), enquanto que a idade óssea média no final do tratamento foi de onze anos e oito meses (dois anos e três meses a mais do que a média da idade no final do tratamento).

- Com relação ao avanço da idade óssea, uma vez que $P=1$, foi indicado que não houve progressão significativa da mesma no decorrer do tratamento, o que está dentro do esperado, uma vez que o uso do análogo de GNRH tem o objetivo de diminuir a progressão dessa idade óssea, com o intuito de que essas garotas tenham um tempo maior para ganharem estatura.
- Além disso, é possível ver que as diferenças entre as dosagens hormonais de FSH e LH também foram significativas, uma vez que $\mathrm{P}=0.029$ e $\mathrm{P}=0.006$ respectivamente, o que indica que o tratamento com análogo foi suficiente para causar uma diminuição desses dois hormônios gonadotróficos, desacelerando o processo de puberdade.

Tabela 1. Comparação das variáveis numéricas entre as avaliações inicial e final.

\begin{tabular}{|cccccc|}
\hline Variável & $\mathbf{N}$ & Média & \multicolumn{1}{c}{ Mediana } & D.P. & Valor-P* \\
\hline Idade1 & 53 & 7.31 & 7.67 & 1.88 & $\mathbf{P}<\mathbf{0 . 0 0 1}$ \\
Idade 2 & 53 & 9.51 & 9.92 & 1.85 & \\
Altura 1 & 49 & 128.37 & 130.00 & 13.52 & $\mathbf{P}<\mathbf{0 . 0 0 1}$ \\
Altura 2 & 49 & 140.20 & 142.00 & 12.64 & \\
I.O.1 & 48 & 9.77 & 10.00 & 2.21 & $\mathbf{P}<\mathbf{0 . 0 0 1}$ \\
I.O.2 & 48 & 11.79 & 12.00 & 2.30 & \\
FSH1 & 17 & 10.88 & 6.20 & 11.67 & $\mathbf{P}=\mathbf{0 . 0 2 9}$ \\
FSH2 & 17 & 4.01 & 4.34 & 2.12 & \\
LH1 & 18 & 4.37 & 3.33 & 4.02 & $\mathbf{P}=\mathbf{0 . 0 0 6}$ \\
LH2 & 18 & 1.66 & 0.93 & 1.72 & \\
\hline
\end{tabular}
comparação entre avaliação inicial e final.

Foram feitas análises estatísticas descritivas das variáveis numéricas, com valores de média, desvio padrão e mediana. Para comparação das variáveis entre as duas avaliações foi utilizado o teste de Wilcoxon para amostras relacionadas, devido à ausência de distribuição normal das variáveis. Programa utilizado: SAS versão 9.2 .

\section{Conclusões}

O tratamento com análogo de GNRH se mostra eficaz no ganho de estatura de meninas com diagnóstico de puberdade precoce central.

${ }^{1}$ Conover, W. J. (1999), Practical Nonparametric Statistics. New York: John Wiley \& Sons, $3^{\text {rd }}$ ed.

2 Villanueva C, Roux N. Neuroendocrine Control of Puberty in Early Puberty: Latest findings, diagnosis, treatment, long-term outcome (Bouvattier C., Pienkowski C.). Springer. Translated from French Edition. 2014. 